\title{
Fakes and Forgeries of Written Artefacts: An Introduction
}

Fakes and forgeries of written artefacts have made their way through all written cultures, past and present, in various ways. In the cultures of Antiquity, scribes already tried to reproduce ancient inscriptions and manuscripts or create new ones imitating archaic scripts, thus producing what we would now call 'antique fakes'. Since the Renaissance, the production of fake artefacts has greatly increased in Europe, a situation similar to developments in China from the eleventh century onwards. These 'modern fakes' refer to written artefacts produced in recent centuries that pretend to be ancient.

Fakes have always been objects of fascination. They are often a response to demands from both the public and the scholarly milieu. Sometimes they are exceptional items that are unique or of particular artistic, scientific or technical interest. When a forgery is detected as such, it obviously results in a feeling of disappointment, but it can also provoke admiration for the virtuosity of its originator and inspire scientists to develop new methods of testing.

There has been a growth in the number of publications dedicated to fakes and forgeries for around thirty years now, many of which have focused on books and literary works. ${ }^{1}$ The topic has also inspired a dozen conferences in the last decade, some of them dedicated specifically to antique fakes. ${ }^{2}$ Among other subjects, these various scholarly events have dealt with the scientific duel between

1 See Myers 1996, Rosenblum 2000 or Landon 2003, among others. Köhler 2015 also includes types of fakes. Freeman 2014 and Havens 2014 are concerned with the Bibliotheca Fictiva, which is a collection of literary forgeries from 400 BCE to the present day. According to Havens (2014, 27), manuscript forgeries are "physical "autograph" specimens that represent the perennial effort of forgers to establish alternative truths in unique written forms ostensibly recorded for the ages by the great figures of literature and history'.

2 For instance, 'Fake and Real in Ancient and Modern Societies - Objects, Places and Practices' (Goethe University, Frankfurt, 15-16 March 2018); 'Faking It - Forgery and Fabrication in Late Medieval and Early Modern Culture' (University of Gothenburg, August 2019); 'Impostures savantes. Le faux, une autre science de l'antiquité' (Paris, INHA, 6-7 May 2015); 'Imitations, copies et faux - Des rives du Nil à Rome' (Paris, Collège de France, 14-15 January 2016, published in Gaber et al. 2018). 
forgers and experts, the debate about truth and falsity, methods of authenticating objects and identifying forgeries, and developments in criticism as a response to forgery. In the same vein, several exhibitions of fakes and forgeries have also taken place since the end of the twentieth century (Lehrer-Jacobson/Jacobson 1989, Jones 1990, and Casement 2015, among others). ${ }^{3}$ Last but not least, there is now a museum in Vienna entirely devoted to fakes: the Fälschermuseum, or Museum of Art Fakes. ${ }^{4}$

Faked written artefacts have often been used to manipulate and modify history, partly for propaganda purposes or to rewrite history by producing apocryphal texts. This was the case for the Karaite inscriptions that Abraham Firkowicz altered or completely invented in the nineteenth century, for example - a Karaite scholar, he aimed to prove that Karaites had settled in Crimea during Antiquity (Dan Shapira and Malachi Beit-Arié).

An important distinction needs to be made here between (i) the act of forging an object, i.e. the written artefact itself, as in the case of the Glozel tablets (Catherine Breniquet), the Lead Books of Granada (Claudia Colini) and the Codice Diplomatico produced by Father Vella (Jan Just Witkam), and (ii) the act of forging the content, i.e. the text written on the artefact, for example by producing text copies and drawings of imaginary written artefacts, as in the case of publications of Greek and Roman inscriptions by Michel Fourmont (Olivier Gengler) and Wolfgang Lazius (Ekkehard Weber).

Some ancient faked written artefacts have been historicised and become part of the history of a society, such as the cruciform Maništušu monument pretending to belong to the third millennium BCE, but actually made by late-first-millennium Babylonian priests (Cécile Michel). Indeed, traditional societies also produced written artefacts that pretended to be something they were not. It may be difficult to decide when such an object and/or its text actually becomes a fake, as in the case of Arabic manuscripts produced in early medieval times (François Déroche). Many fakes can now be found in museums and collections around the world, but their identification is problematic. Several questions arise as to how they were made, what their originator's profile was and why they were made in the first place.

3 Also see Unearthing the Truth: Egypt's Pagan and Coptic Sculptures, February 2009, Brooklyn Museum; 'Intent to Deceive: Close Examination: Fakes, Mistakes and Discoveries' (London National Gallery, 30 June-12 December 2010); 'Fakes and Forgeries in the Art World' (Springfield Museums, 21 January-27 April 2014) and earlier exhibitions mentioned in Craddock 2009, 6.

4 The museum, which is dedicated to paintings, opened in 2005 and is at Löwengasse 28, 1030 Vienna, Austria. Its website is at $<$ https://neu.faelschermuseum.com/> (last accessed on 29 March 2020). 
This volume, which presents thirteen contributions devoted to fakes and forgeries of written artefacts, covers both a long chronological scale and a wide geographical area, with a focus on Mediterranean, Islamic and Chinese cultures. The oldest fakes date back to the beginning of writing in Mesopotamia, while the most recent forgeries date to recent decades and were produced in China (Michael Friedrich) and Italy (Ira Rabin and Oliver Hahn). These studies are aimed at understanding the subtle distinctions conveyed by a developed vocabulary related to the reproduction of ancient artefacts and the production of artefacts claiming to be 'old': from copies and replicas to fakes and forgeries. A wide variety of methods are employed to produce fake written artefacts, which relate to the material they are made of, their content or both aspects.

The forgers often come from a scholarly milieu. Their motives for producing such items may be economic, political, religious or personal, such as aspiring to fame or playing a joke on fellow scholars. What these fakes have in common is their makers' intention to keep their quality of being fake secret. So how can we possibly identify them? Combining the study of contents, codicological, epigraphic and palaeographic analyses and scientific investigations helps experts to detect forgeries (Jost Gippert). However, there are several famous unsolved cases for which modern technology has been unable to provide a clear answer (Craddock 2009, 3). Nowadays, one finds fake artefacts in museums and private collections alike, but they can also be found on the antique market, mixed with real artefacts that have often been looted. The attitude of the scientific community towards these objects requires ethical reflection.

The following introductory remarks will initially address the terminology used in this volume, then deal with the making of fakes and the background and motives of their producers. Towards the end, we will discuss the identification of fakes and the ethical problems associated with them. The focus will be on written artefacts here, occasionally drawing on other domains if they can contribute to a better understanding of the former.

\section{Terminology}

The very notion of fake or forgery presupposes a concept of 'original', 'genuine' or 'authentic'. The idea of 'copy' is defined by its relation to an 'original', too, albeit in a different manner. The understanding of these terms may vary according to place, time and the type of artefact considered. In China, for example, oil paintings from the famous village of Dafen that reproduce earlier works are considered as originals by some people, referring to the centuries-old tradition of 
copying in calligraphy and painting. In the Western world, however, these are regarded as copies or replicas. ${ }^{5}$ In addition, what we categorise with these words today could have been understood differently in ancient times or even a few centuries ago. In medieval England, for instance, documents were faked for various reasons, including the necessity to reproduce originals which had been lost or the need to provide evidence of a narrative that was believed to be true, thus making it part of an alternative historiography (Hiatt 2004). Jones (1992, 7-10) suggests that the concept of authenticity was much more flexible in the sixteenth and seventeenth century than the one that has developed since the nineteenth century. What's more, when the words 'fake', 'forgery' or 'counterfeit' are applied to a written artefact that is not genuine, they can cover a wide range of meanings depending on the motives behind its production. The different understandings of these terms therefore require some clarification. This also implies a discussion of their antonyms, such as 'authentic' or 'genuine', and of the vocabulary linked to the various forms of copies that exist.

An 'authentic' monument, object or written artefact is often depicted as an 'original" of known origin and context. The word 'authentic' has more or less the same meaning as 'genuine', ${ }^{8}$ which is an antonym of 'fake'. According to Craddock (2009, 8), however, the concept of authenticity is 'fluid' to archaeologists and art historians. For some scholars, the object itself must be original in terms of its materiality, while for others, it should preserve strong links with the original object, although large parts of it may have been restored. The degree of restoration work undertaken on an ancient artefact in the eighteenth and nineteenth century may compromise its authenticity in today's perception (Vaughn 1992, 42). As an example, the nineteenth-century restoration of the Sargon Palace reliefs at Khorsabad showing the transporting of logs assembled as rafts on the Mediterranean has turned a crab, a marine animal, into a crayfish,

5 Besides creating new works, thousands of professional painters, many of whom are graduates of art schools, produce copies of known works in Dafen that can be ordered online; see the list of famous painters they copy at their online shop <https://www.dafenvillageonline.com/ $>$ (last accessed on 9 May 2020).

6 Oxford English Dictionary 2020, sub 'authentic, adj. and n.': '7. Genuine; not feigned or false [...] a. Of a document, artefact, artwork, etc.: having the stated or reputed origin, provenance, or creator; not a fake or forgery. [...] c. Presenting the characteristics of the original; accurately reproducing a model or prototype; made or done in the original or traditional way'.

7 Oxford English Dictionary 2020, sub 'original, adj. and n.': '1.b. spec. Designating the thing, as a document, text, picture, etc., from which another is copied or reproduced; that is the original'. 8 Oxford English Dictionary 2020, sub 'genuine, adj. '”: '3. Really proceeding from its reputed source or author; not spurious; = authentic adj. 7a'. 
a freshwater animal (Michel/Lion 2000). After the fire that destroyed the roof of the iconic Notre-Dame Cathedral in April 2019, a debate developed about the type of restoration that should be carried out during its reconstruction: should the spire added by Eugène Viollet-le-Duc during the previous restoration of the building in the nineteenth century be preserved or not? Thus, the question here is how far the restoration - the recreation of the building's 'original' appearance should respect the original work (see also Cécile Michel's comments on the reconstruction of the walls of the processional street of Babylon in this volume.)

In the early twentieth century, conservators at the India Office Library dissected scrolls from Dunhuang into the sheets they were composed of and bound them in leather volumes for archival storage (Van Schaik/Galambos 2012, 77). Nowadays, conservators do not usually try to restore the 'original' state of an artefact or neglect its present state, but preserve the object as they find it, with all its blemishes and traces of later interventions. If new interventions are necessary, the current thinking is that these should be reversible and well-documented. This not only holds true for monuments, but for written artefacts, too, and nicely demonstrates how the changing label of an 'original' may justify the opposite practices when it comes to handling objects.

A 'copy' intends to imitate the original object. ${ }^{9}$ If it is more or less identical as an artefact and in terms of its content, it can be called a 'duplicate', as are documents issued by legal and administrative authorities, or a 'replica', ${ }^{10}$ a term more commonly used for works of art. In China, copying has been done widely in order to preserve originals - for centuries in some cases. The dividing line between a copy and a fake can be very tenuous, as the training of scribes and calligraphers in several cultures was based on the reproduction of model writings (François Déroche, Uta Lauer and Michael Friedrich). Replicas made with the same materials and possibly in the same workshop as the original may become originals in turn. In other instances, replicas made for conservation purposes may become objects of tourism, as if they were originals. In France, for instance, in order to preserve the unique prehistoric cave paintings found in the Lascaux cave, no less than two replicas of the cave were made for visitors. ${ }^{11}$ Museums sometimes

9 Oxford English Dictionary 2020, sub ‘copy, adj. and n.': '2. A writing transcribed from, and reproducing the contents of, another; a transcript. [...] 3. A picture, or other work of art, reproducing the features of another. [...] 4.a. Something made or formed, or regarded as made or formed, in imitation of something else; a reproduction, image, or imitation'.

10 Oxford English Dictionary 2020, sub 'replica, n. (and adj.)': ‘3.a. A copy or duplicate of a work of art, esp. a copy made by the original artist'.

11 Lascaux II in 1983. Lascaux IV, which is a complete replica, was opened in 2016. See $<$ https://archeologie.culture.fr/lascaux/fr> (accessed on 29 March 2020). A full replica of the 
present moulded replicas of valuable or fragile objects, or of originals presented elsewhere, and publishing houses produced expensive facsimiles of manuscripts, at least up to the advent of open access digital images in the internet. An 'imitation'12 is also made from an original; it is inspired by it without necessarily reproducing it identically, as a 'replica' does. Roman statuary was a source of inspiration for both ancient Roman and later artists who produced a great number of pseudo-Roman statues.

There are three main terms in English that refer to non-genuine artefacts that pretend to be genuine: 'fake', 'forgery' and 'counterfeit'. 'Fake' is used as a generic term applied to an artefact that is made to look like something it is not. The object is also sometimes referred to as a worthless imitation that is intended to deceive people. This term evokes a whole range of meanings from erroneous to falsification, i.e. altering an artefact or a document to deliberately mislead people. ${ }^{13}$ The word 'counterfeit" ${ }^{14}$ corresponds to an imitation of a physical object, often implying inferior quality. 'Forgery' is the process of fraudulently making, adapting or imitating objects, or the result of this process - an object that is made to look real or valuable - with the intention of deceiving or cheating people. ${ }^{15} \mathrm{~A}$ forger shapes an object that is artistically, stylistically and technically realistic and corresponds to the period to which this object claims to belong (Craddock 2009, 61). Forgery is a crime punishable by law. Thus, the term 'forgery', a subcategory of 'fake', is mainly used in cases dealing with a legal aspect. However,

Palaeolithic painted cave at Chauvet, a UNESCO world heritage site in France, was made with the help of digital tools and was opened to the public in 2015. See <https://archeologie.culture.fr/ chauvet/fr> (accessed on 29 March 2020).

12 Oxford English Dictionary 2020, sub 'imitation, n.': '2. The result or product of imitating; a copy, an artificial likeness; a thing made to look like something else, which it is not; a counterfeit'.

13 Oxford English Dictionary 2020, sub 'fake, n. ${ }^{2}$ and adj.': 'A.5. An object intended for use in a particular manner indicated by the context; a contraption, a gadget; (in later use chiefly) an item used by a conjuror to perform a particular trick or tricks. [...] Originally apparently without specific implication of dishonesty or deception, but in later use not always easily distinguished from sense A. 6. [...] 6. Originally U.S. Something which has been faked; esp. something which has been counterfeited or forged, or which has been fraudulently modified in order to give it the appearance of something else; a forgery'.

14 Oxford English Dictionary 2020, sub 'counterfeit, adj. and n.': 5.a. Of material things or substances: Made in imitation of something else, 'imitation', not genuine; made of inferior or base materials; spurious, sham, base (esp. of coin)'.

15 Oxford English Dictionary 2020, sub 'forgery, n.': ‘3.a. The making of a thing in fraudulent imitation of something; also, esp. the forging, counterfeiting, or falsifying of a document'. 
the verb 'to forge"16 has a wider meaning including 'to produce a fake' or 'to fake'. ${ }^{17}$

These terminological considerations are only meant to serve as an orientation since the use of these terms is often not precise, not even in scholarly writing. Beyond the idiosyncrasies of individual scholars, each field of scholarship has its own linguistic conventions and established ways of referring to objects and practices, therefore the editors have refrained from trying to standardise the use of terms in the contributions to this volume. In general, however, the following distinctions may be helpful:

- 'Fake' refers to all objects and contents produced with the intention to deceive, whether just for fun, for profit or for higher aims.

- 'Forgery' is a term involving the production of a fake item, which can potentially have legal consequences.

- 'Copy' is a neutral term for duplicating a complete artefact or parts of it; a copy may serve educational or further honest purposes or it may be produced in order to deceive.

- A 'replica' is a copy which duplicates a complete artefact perfectly.

With the exception of 'replica', the first three terms in colloquial usage may refer to a complete physical object, the artefact, including its written content, or only to the content. Sometimes fake content is written on an authentic material or added to a genuine written artefact, and in other cases fake content is given a fake provenance or even a fake archaeological context.

\section{Producing fakes}

A wide variety of fake artefacts can now be found in antique shops, museums and private collections all over the world. The processes involved in their design, manufacture and presentation are highly diverse. In general, two types of fakes

16 Oxford English Dictionary 2020, sub 'forge, v. '": '5.a. To make (something) in fraudulent imitation of something else; to make or devise (something spurious) in order to pass it off as genuine. [...] b. To imitate fraudulently; to counterfeit'.

17 Oxford English Dictionary 2020, sub 'fake, v.'? '4.a. transitive. To tamper with or modify (something) for the purpose of deception, or for some other dishonest or illicit purpose. 7.b. transitive. To make (something) in imitation of something else, generally with the aim of misleading or defrauding someone; to counterfeit, falsify, forge; to fabricate (something false or non-existent)'. 
can be distinguished, namely copies or replicas of an original on the one hand and objects only resembling authentic artefacts on the other. The latter are often produced for the tourist market nowadays and are usually easy to identify. ${ }^{18}$

Many fake items are produced by copying. They are created either by imitating an authentic object by hand or by reproducing it using a specific technique such as moulding. In the first case, the forger must be skilled enough to reproduce the original very closely using traditional materials and techniques so that a non-expert would not spot any difference between the original and its handmade replica. This practice is widespread with regard to paintings, for example, and allows forgers to produce close substitutes of a limited number of precious objects (Jones 1990, 29-30). As for ceramics, original materials may be used, which makes identification a high-tech enterprise (see Museum für Asiatische Kunst 2007).

The second technique, which is also readily attested in Antiquity, consists in reproducing the object in question by casting. A mould is made from the original, which can allow it to be reproduced at will, depending on which moulding process is chosen. A technique of this type was widely used in the late nineteenth and early twentieth century to obtain hundreds of fake cuneiform tablets, for instance (Cécile Michel). However, these are easy for experts to identify because tablets were reproduced in two halves, then joined together in such a way that the joint between the two pieces is visible.

Today, new methods such as electrotyping and 3D printing are being used to make fake artefacts intended to deceive people or to make replicas for cultural heritage purposes. The development of new methodologies and technologies to detect fakes has been accompanied by the growing progress made by forgers who produce such artefacts, though. Some forgers have created fakes by transforming authentic written artefacts - Abraham Firkowicz transformed letters and numbers on real tombstones to make them several centuries older than they really were, for example (Dan Shapira, Malachi Beit-Arié). Other forgers have shaped fakes by imitation, using a known language and script to invent a new text. There is a general tendency to use archaic forms of language and writing with the idea of obtaining more credible forgeries (Grafton 1990, 54); many Roman inscriptions were forged from Antiquity onwards, for instance (Barker 1990; Ekkehard Weber). The Arabic language and script have inspired many counterfeiters attracted by the aesthetics of calligraphy (Gallop 2017; François Déroche). Giuseppe Vella created his Arabic Codex Martinianus by pretending it belonged

18 In forensic document analysis, this is called 'simulated' vs. 'simple'; see Koppenhaver 2007, 56. 
to the Aghlabid dynasty in Tunisia (Jan Just Witkam), and the holy Lead Books of Granada, which are written in archaic Arabic characters, were the subject of a long dispute between Spain and the Vatican (Claudia Colini).

Many such fakes were produced and sold with mixed success throughout history, depending on the credulity of potential buyers. Denis Vrain Lucas (18161881) managed to sell a considerable number of fake Old French letters to the mathematician Michel Chasles (1793-1880), a member of the French Academy of Sciences, claiming they were written by Alexander the Great, Aristotle, Pythagoras, Racine, Galileo, Molière and Pascal; Lucas even suggested that Pascal had discovered the Law of Universal Attraction before Newton (Bloch 1941, 57), and Chasles obviously believed him.

In some instances, forgers faked the content of a written artefact on an old, authentic item to make it seem genuine. The Jehoash inscription in Old Hebrew, which describes the repairs made to the Temple of Jerusalem by the king of Judah (2 Kings 12), is one such case - a modern inscription made on an antique limestone tablet (Greenstein 2016). The same collection belonging to the controversial antiquarian Oded Golan included a pomegranate made of hippopotamus ivory and covered with an ancient Hebrew inscription. It was thought to have been placed on the top of the sceptre of Salomon, the temple priest. However, according to experts at the Israel Museum, it could actually be a fake inscription made on a very old artefact; the debate about the status of the inscription is still going on (Ahituv et al. 2007). Other forgers did not bother to produce the artefact itself, but published a hand-made copy that they claimed to have made from it, thus fabricating a fake mentally rather than materially (Lowenthal 1990). This is what Abraham Firkowicz did with his Karaite manuscripts, for instance, or what Father Vella did with most of his Codice Diplomatico.

Michel Fourmont did not create the artefacts either, but made drawings of imaginary inscriptions (Olivier Gengler). However, unlike the previous forgers mentioned, Michel Fourmont invented a completely new alphabet to support his story; he even thought about publishing partially broken texts to make his fake inscriptions look more convincing. The originator of the Glozel tablets actually created a new script, which would supposedly have made it the oldest one in the world if it had been genuine, but no language was identifiable with it (Catherine Breniquet). Moreover, Glozel's clay tablets were all the more suspect because they were all intact despite them having been found in the soil in a field; had they been real, some of them would have been broken.

On the market, broken antiquities are not as easy to sell as whole ones. Dealers may therefore be tempted to get intact copies, embellishing damaged antique objects, which are then more sellable (Jones 1990, 247). In other instances, 
authentic written artefacts are broken on purpose so the dealers can increase their profits by selling two or three antiques rather than just one. ${ }^{19}$

\section{Forgers' backgrounds}

The variety of methods used to produce fake artefacts reflects the different personalities forgers have, and some of the methods go back as far as Antiquity. In China, fake calligraphic works from the fifth century have been reported, for example. The growing market for works of art from the great masters was fuelled even more when a first wave of antiquarianism developed in the eleventh century (Michael Friedrich, Uta Lauer). In European history, fakes flourished from the Renaissance onwards - the great age of explorations and discoveries - with the growth of collections of antiques, and forgers showed considerable imagination when it came to producing such items (Havens 2014, 13; Stephens 2014). During the sixteenth century, scholars devoted themselves to uncovering lost texts from Antiquity, and inspired by the new discoveries, some of these learned people created their own 'ancient' manuscripts and inscriptions, sometimes inventing a whole new world. Wolfgang Lazius (1514-1565), a renowned epigrapher, published a large number of genuine Roman inscriptions, but also forged some with the aim of consolidating his historical discourse (Ekkehard Weber). Apart from spending their time reading and writing in libraries, a number of scholars also started to go out into the field to make more discoveries themselves, an attitude that testifies to an evolution in humankind's relationship with his past (Schnapp 1993).

At the same time, criticism was developing and progress was being made in identifying forged written artefacts (Grafton 1990, 123; Hiatt 2004, 181-187), contributing to what would be called 'auxiliary sciences' later. This required forgers to be more skilful in their production. Michel Fourmont (1690-1746) was sent to Constantinople and Greece by the King of France to find ancient manuscripts for the royal library. Since he was unable to trace and acquire such documents, he collected Greek inscriptions from several sites in the Peloponnese and Sparta instead. He increased the number of his discoveries by producing a considerable amount of fake inscriptions himself, however (Olivier Gengler). Arabic or quasiArabic texts presumably dating to the Islamic domination of Sicily were actually

19 This is the case for some cuneiform tablets that exhibit a clear break, which was presumably made deliberately. 
invented by Guiseppe Vella at the end of the eighteenth century (Jan Just Witkam).

The production of fakes increased during the nineteenth and early twentieth century. Some of the counterfeiters hid their fake artefacts in large collections of authentic items. Thus, Abraham Firkowicz (1786-1874), renowned for having collected more than fifteen thousand Jewish manuscripts, also 'corrected' the inscriptions on tombstones in his publications and composed fake ones (Dan Shapira, Malachi Beit-Arié). In the majority of cases, though, the identification of a written artefact as a fake does not mean the name of its creator is known.

When a forger is identified, it often turns out that he (or she) belongs to a scholarly or religious milieu. In Mark Jones' view (1990, 12), 'the fake itself is evidence of the historical sense of its maker and recipients', and in Anthony Grafton's opinion $(1990,48)$, the desire to forge something can infect almost anyone. The different examples presented in this volume, which concern faked written artefacts, were largely made by educated forgers - people who acquired sufficient knowledge and skill to create credible fakes capable of deceiving their colleagues. Among these 'artisans', there are historians, philologists and archaeologists such as Wolfgang Lazius (Ekkehard Weber) and Pirro Ligorio, who also worked in the sixteenth century, producing almost three thousand fake inscriptions in all (Metzger 1997, 125). The expression 'forger' may also be applied to certain famous contemporaneous scholars, such as James Mellaart (1925-2012), who was known for his discovery of the Neolithic site of Çatal Höyük in Turkey. He was banned from the country in the 1960s, however - for illicitly trafficking antiquities. In fact, he was recently suspected of having produced the inscriptions and paintings he had claimed to have found all by himself. ${ }^{20}$

Having access to original artefacts is an important factor for fakers. Marino Massimo De Caro, a former director of the Girolamini Library in Naples, Italy, and the man behind the theft of many of its valuable old books, made a complete copy of Galileo's Sidereus nuncius published in 1610, adding unique hand-painted watercolours of views of the moon signed with Galileo's signature. This truer-thanlife achievement fooled scholars for a decade before they realised what had really happened (Ira Rabin and Oliver Hahn; Bredekamp et al. 2014). There is no doubt that the forger was only able to carry out his work because he had access to the original book. For the same reason, some forgers were also able to act as merchants or were in close contact with merchants selling authentic written

20 See <https://www.livescience.com/61989-famed-archaeologist-created-fakes.html> and $<$ https://luwianstudies.org/app/uploads/2018/03/LS_MI_20180301_Mellaart_ENG.pdf> (accessed on 29 March 2020). 
artefacts and fakes at the same time. The Ready brothers, who presumably produced a large quantity of fakes in the late nineteenth century, were officially employed by the British Museum to produce replicas and were in close contact with Joseph Shemtob, an antiquarian who sold thousands of cuneiform tablets in Europe and North America (Cécile Michel). Konstantinos Simonides (1820-1890) is another famous philologist who was both a merchant and a forger of antiquities. He sold biblical manuscripts which are now thought to have been fakes created with his own hands (Müller et al. 2017). Those in charge of restoring antique objects also possess the knowledge and skills necessary to produce fakes themselves (Tait 1992). Merchants selling antiques may acquire such knowledge to fool their own customers, as Moses Shapira has demonstrated. Fakes produced by artists are a special case in point here: in Islamic and East Asian traditions, the art of calligraphy is practised by erudite artists and scholars alike, and both are prone to the temptations of faking. In China, calligraphers not only copied the works of great masters, but their own works as well if there was a demand for them, so they produced or authenticated fakes (François Déroche, Michael Friedrich).

If forgers had to be well educated to produce fake manuscripts and inscriptions, it is hard to understand how someone like Émile Fradin, a poor, sixteenyear-old farmer boy, could have produced clay tablets bearing a completely new script, possibly inspired by the Phoenician alphabet, at the beginning of the twentieth century. The mystery of the identity of the Glozel inventor(s) and his (or their) motives is still unsolved (Catherine Breniquet).

\section{The forgers' motives}

Legitimate copies or replicas of antiquities and works of art are made for practical purposes such as protecting the original work or for display purposes if the original itself is too fragile to be handled; these reasons are openly admitted by the manufacturers. But at times, some of these copies are turned into fakes or serve as a source of inspiration to forgers (Harrist 2004, 34; François Déroche). Fake artefacts that are allegedly authentic are actually clandestine copies or artefacts intended to deceive people. Forgers have a wide variety of motives for producing fakes, such as financial gain, historical, cultural, political or religious reasons, social ambition or professional recognition, or simply for their own amusement. Even hatred of a colleague can be a reason (Grafton 1990, 36-68; Higbie 2017, 12). Fakes may be intellectual projects intended to serve as evidence to confirm the ideas and hypotheses of their originators. In many cases, the motivation behind 
them is far from simple, being intertwined with the beliefs and opinions of the forger and the wishes of the recipients. This is highlighted in the case of the Lead Books of Granada, for instance (see Claudia Colini quoting Elizabeth Drayson 2013, 111).

Fakes have been made for economic reasons ever since ancient times. This was what motivated the Babylonian priests who were hoping to see their crown endowment increase by making the apocryphal Maništušu cruciform monument, for example. The growing production of fakes from the eleventh century in China or the European Renaissance to the early twentieth century corresponds to an increasing demand born out of a fascination about antiquities (Jones 1990, 119 and 161). The collecting 'mania' concerning ancient artefacts is no longer limited to scholars or rich aristocrats, but has spread more widely in society. Forgery can be a lucrative business, with a market that is often accessed by poorly educated buyers. This is what makes forgers cut genuine clay cuneiform tablets that are still intact into two or three pieces or cut pages out of old volumes to sell them individually and make more money. Sometimes, ordinary manuscripts are turned into luxury items embellished with calligraphy (François Déroche) or images (Obi/Müller 1997, 56). The many fake Roman inscriptions sold by scholars and adventurers alike were marketed with the aim of making money (Ekkehard Weber). The case of the Glozel tablets in France is quite unusual here, however, as it was presumably not the forger who took advantage of his fakes, but the owner of the field where they were supposedly found; the young man, who was a teenager at the time of the 'discovery', made a business out of it, which he exploited throughout his long life, arranging tours for curious tourists, setting up a museum about the finds, writing and publishing books on the matter, and so on (Catherine Breniquet). The market for fakes grew smaller during the first half of the twentieth century as detection methods become more effective. In the last few decades, however, the production of fakes rose again due to various factors, such as the wars in the Middle East and China's entry into the international art market. In addition, famous cases like the forged diaries of Hitler (1983) and Jack the Ripper (1992) demonstrate the unbroken attraction of trying to fool the experts as well as the general public (Koppenhaver 2007, 52-53).

From Antiquity onwards, the production of fake antiques served historical and cultural purposes. Their originators, often learned priests or monks, believed that these objects descended from the glorious ancient civilisations of Babylon and Egypt, and they tried to use the power of the past to impact the present, thus attempting to rewrite history (Jones 1990, 59-60). They gathered genuine written artefacts and created fakes with them to prove such links (Grafton 1990, 41); Father Michel Fourmont created a corpus of Spartan texts to prove the Semitic 
origin of the city, for example (Olivier Gengler), and Brother Guiseppe Vella invented an early Arab history of Sicily (Jan Just Witkam). The mastermind behind the Glozel fakes, in contrast, wanted to demonstrate that the Occident had played a role in the foundation of our societies by developing the very first writing system as early as the Neolithic period.

All forgers are active in social, economic and political settings, which encourage and inform their work. If there is a market for certain objects, then these objects will be created, if necessary by forging them. Besides simply serving market interests, however, there are more sophisticated demands that forgers try to satisfy as well, such as religious or political needs. Abraham Firkowicz transformed and produced inscriptions and manuscripts in order to prove that Karaite Jews had moved to Crimea centuries before the crucifixion of Jesus Christ, for instance; he was successful, too, as Karaites not only escaped persecution, but also received protection from Russia (Dan Shapira, Malachi Beit-Arié). The Lead Books of Granada were used as political and religious tools both by the forgers and their opponents, depending on the interpretation given to them (Claudia Colini). Numerous forgeries that were intended to prove the truth of the Bible have been identified, such as the Jehoash tablet or the sixteen pseudo-Dead Sea Scroll fragments that were bought by the Museum of the Bible in Washington. ${ }^{21}$

A social group, an institution or even a state may try to adjust to a new situation by making historical claims, especially in times of political change. The reinterpretation of history is, of course, greatly facilitated by the discovery of 'original' artefacts proving such claims. In China, even archaeology has had to contribute to linking the modern Chinese state with the distant past. Thus, ancient manuscripts containing texts which supported contemporary ideas were welcomed by many scholars (Michael Friedrich).

If a willingness to discuss seemingly improbable hypotheses did not exist among scholars, however, then the higher art of forgery would soon be out of business; scholars and scientists are exposed to and influenced by the opinions and prejudices of their time, but some of them have preconceived ideas of their own, making them unable to see a fake artefact when it is in front of them because they want to see what it actually purports to be, as in the case of the Sidereus nuncius forgery (Bredekamp et al. 2014).

The 'discoverers' of forgeries that aim to change the course of history are sometimes the forgers themselves with the secret wish of becoming famous. Some scientists have succumbed to fraud because of their own social and professional

21 <https://www.nationalgeographic.com/history/2020/03/museum-of-the-bible-dead-seascrolls-forgeries/> (accessed on 29 March 2020). 
ambitions, seeking recognition from the scientific community and more widely from society in general. This was presumably what drove Wolfgang Lazius to forge Roman inscriptions (Ekkehard Weber), or what went through Michel Fourmont's mind, as he yearned for honour and glory despite facing pressure for not having accomplished his official mission (Olivier Gengler).

There are many other reasons why scholars produced fakes, such as wanting to trick their colleagues, students or professors, especially on archaeological excavations - sometimes for personal amusement, but professional rivalry and even hatred played a role as well (Havens 2014, 1). Motives of this kind seem to be behind the three inscribed Davenport tablets discovered in 1877 by Reverend Jacob Gass during an emergency excavation at a Native American burial mound in Iowa. The tablets include representations of hunting and cremation, an astronomical table and writing in an unknown script. According to Marshall McKusick (1991), these artefacts must have been placed in the excavation area by jealous members of Davenport's academia. He suspects the 'tablets' were actually modified roof tiles from a nearby building.

A case in its own right concerns Zhang Daqian (1899-1983), one of the most famous (and expensive) Chinese painters of the past century. He liked fooling the experts, and since 'he felt he was an equal to the old masters', 'the true test was whether he could copy them' (Barboza et al. 2013). There are many stories about him. One of them reports that when he was shown works by famous Chinese painters from the last dynasty in a North American museum, he burst out laughing, saying he had done quite a few of them himself. In 2007, the Museum of Fine Arts in Boston dedicated an exhibition to him with the telling title 'Painter, Collector, Forger. ${ }^{22}$

\section{Identifying fakes}

According to Jones (1992, 9), 'questions of motive are perhaps less important than the quality and impact of the result'. While important progress has been made in detecting fakes by scientific analysis, counterfeiters' ability to make fakes that look like authentic artefacts has been growing at the same time (Lowenthal 1990). They now have a better understanding of the physical and chemical processes of corrosion and natural ageing, for instance (Craddock 2009, 10-12). Forgers may also be helped if they have access to radiometric data (Ira Rabin and Oliver

22 See <https://www.mfa.org/exhibitions/zhang-daqian> (accessed on 26 April 2020). 
Hahn). This explains the endless debates on certain emblematic artefacts. The Silwan ossuary, for example, which was discovered in 2002, bears an inscription suggesting that it belonged to 'James, son of Joseph, brother of Jesus'. Numerous examinations and counter-examinations by experts have been unable to prove that it is either a forgery or an authentic ossuary. ${ }^{23}$ In other cases such as antique bamboo manuscripts acquired by Chinese public institutions in recent years, doubts concerning their authenticity have remained because the artefacts have either not been tested using scientific methods or the test reports have not been published (Michael Friedrich). In fact, in forensic science, even the experts disagree about methods and results (Fisher 2008).

Fakes may be detected from a historical, archaeological, artistic or philological point of view or from a natural science perspective, the latter being based on tests involving a large number of technologies (Ira Rabin and Oliver Hahn). This implies the need for collaboration between disciplines. One important way of identifying a fake is by tracing its provenance back to the time it was made (Tait 1992). Although this is obviously impossible when dealing with antique objects, an analysis of their original context is still very important. As Craddock has noted $(2009,16)$, forgers and dealers often add an archaeological background to their creations. However, objects found during archaeological excavations need to be consistent with the archaeological layer in which they were exhumed and with the artefacts discovered in connection with them; there should not be any anachronism. The Glozel tablets were found along with a mixture of objects from very different periods (from the Neolithic onwards), and the only archaeological structure was dated to the Middle Ages (Catherine Breniquet).

The situation is complicated even further by fakes made in the past, as very old items frequently appear in more recent archaeological strata. In cases like this, the materiality of the written artefact, the layout of the text, the shape of the script, the language and the textual content all have to match up and fit the period and culture they are supposed to belong to. In some instances, the media may be authentic, like the Jehoash tablet or dismembered pages of ancient books that were used to make fake items (François Déroche). In other cases, suspicion may arise from the script or text having too much originality, as in Michel Fourmont's pseudo-discoveries, in which the shape of the letters had no parallel and the morphology of the words was unique (and quite impossible) (Olivier Gengler). Other reasons for scepticism in the past were the poor recurrence of sign

23 See <http://www.biblicalarchaeology.org/daily/biblical-artifacts/artifacts-and-the-bible/isthe-brother-of-jesus-inscription-on-the-james-ossuary-a-forgery/>, for example (accessed on 29 March 2020). 
sequences on the Glozel tablets which could not fit with a language (Catherine Breniquet) or the many contradictions and linguistic errors observed in the Lead Books of Granada (Claudia Colini). In this last case (and several others as well), the debate about authenticity lasted for a very long time, and this had a damaging impact on the reputation of the scholars involved in the debate.

The archaeological context in which an artefact originated is generally unknown when it first appears on the antique market. Items of this kind usually end up in a private collection or museum. In the latter case, if they are not identified as fakes beforehand, then they are likely to be exhibited in a showcase along with various authentic objects, as they are thought to be genuine. When curators realise that they are fakes, though, the artefacts may well get hidden from view in the museum's storerooms. Alternatively, the items may get exhibited for educational purposes since they are real examples of fakes (Casement 2015). The Musée Postal de Paris used to have showcases containing letters from different periods, including some written on fake clay tablets, for example (Michel 1987, 12-13), and the Israel Museum exhibited an inscribed ivory pomegranate to the general public in order to explain the process of identifying a fake (Rollston/Parker 2005). The Asiatisches Museum in Berlin presented Chinese ceramics pretending to date to the Neolithic Period or Han era, at the same time discussing their production techniques and the scientific methods employed to reveal their true nature (Museum für Asiatische Kunst 2007). Other museums may have been tempted to exhibit replicas, but passing them off as what they are not. In the case of painting replicas, for instance, the card in the showcase could say 'from the school of [name of the artist]' or 'from the workshop of NA', or even 'attributed to NA' (Bohn 1999). Exhibiting replicas instead of authentic artefacts makes sense at a time when the credit given to culture is declining and rules on purchasing works of art and antiques are getting stricter and stricter.

\section{Fakes and looted artefacts on the antique market}

The antique market has become more important in recent years, which is linked to the looting of archaeological artefacts that has ravaged the Near and Middle East for decades. It also plays an important role in the sale of looted Asian antiquities. Artefacts on sale on the antique market do not come from scientific excavations; they have either been torn from their archaeological context thus being deprived of half of their data (Michel 2019, 143), or they are simply fakes. 
Indeed, even though the production of fakes may have declined since the middle of the twentieth century, it is still going on because of the very high prices that authentic antiquities fetch on the market and the growing popularity of cultural heritage (Lowenthal 1990; Luke/Kersel 2005).

Most of the important museums around the world have stopped acquiring artefacts without a context and proof of their provenance, as they wish to avoid buying fakes or objects acquired illegally. The latter are described in the UNESCO Convention of 14 November 1970, which concerns the 'Means of Prohibiting and Preventing the Illicit Import, Export and Transfer of Ownership of Cultural Property'. ${ }^{24}$ On the basis of this declaration, which was signed by a great many countries, scholars now use the non-exclusive term 'object of unknown provenance' to refer to any archaeological object acquired after 1970, considering that it is likely to have been acquired illegally (Michel 2019, 142). This convention does not explicitly include fakes considered as being of 'unknown provenance'.

The value of fakes - once they have been identified as such - is very low unless they are considered to be real artefacts. In May 1994, a report was published under the UNESCO umbrella concerning the feasibility of introducing an international code of ethics for dealers in cultural property..$^{25}$ The report included a discussion of the definition of the word 'dealer', suggesting that this term should be limited to individuals with a degree of knowledge of the material being dealt with and able to discern fakes and forgeries (section 68). However, this point was left out when the International Code of Ethics for Dealers in Cultural Property was approved in November $1999,{ }^{26}$ the idea being that no dealer whatsoever should escape the control of this adopted code.

Unfortunately, some smaller museums and private individuals are not concerned about ethical considerations and are ready to buy any antiquity, whether or not its provenance is known and even if they are aware it has been stolen. These customers generally try to avoid acquiring any forgeries, but they lack documentation proving the origin of their acquisitions and their scientific interest. Eager to prove that their collections only consist of genuine artefacts, they regularly contact scholars who are able to authenticate these artefacts for them, although some of the items have been acquired illegally. The more famous

24 <https://unesdoc.unesco.org/ark:/48223/pf0000133378> (accessed on 29 March 2020). Also see Luke/Kersel 2005.

25 The report is entitled 'Feasibility of an international code of ethics for dealers in cultural property for the purpose of more effective control of illicit traffic in cultural property' (15 May 1994), <https://unesdoc.unesco.org/ark:/48223/pf0000098554> (accessed on 29 March 2020).

26 International Code of Ethics for Dealers in Cultural Property (November 1999), <https: //unesdoc.unesco.org/ark:/48223/pf0000121320> (accessed on 29 March 2020). 
the scholar, the higher the remuneration for an assessment - and the lower the degree of transparency.

The scientific community is divided on how to deal with artefacts whose provenance is unknown, even more so where written artefacts are concerned, as they often have a high value on the market and may have important historical, political or religious implications. For example, North-West Semitic written artefacts connected to the Bible have emerged in recent decades, and several scholars have been tempted to publish this important new data, thus authenticating artefacts which, in some cases, were shown to be forgeries. As noted by Vaughn and Rollston (2005), some of these scholars have been accused of complicity even if they acted in good faith, believing they were dealing with genuine artefacts.

Researchers must be able to conduct their research freely in order to advance knowledge and defend scientific truth. Those who study these objects believe they are saving them from oblivion: the historical importance of their contents would take precedence over everything else. Others, including archaeologists, feel that if scholars are free to carry out their research, then they must also be responsible for it. While the publication of ancient artefacts confirms their authenticity and gives them legitimacy, it also boosts their monetary value. This, in turn, fuels the antique market for ancient written artefacts and encourages the looting of sites and the production of forgeries.

There is no clear answer to solve this dilemma, but an ethic and responsible attitude should prevail in any case. The origin of artefacts must be investigated, and if they are found to have been acquired illegally, then scholars must inform the collector he may have been complicit with looters by buying the items. Moreover, they have to ensure the preservation of the artefacts and work for their repatriation to their country of origin (Michel 2019, 143). Craddock $(2009,21)$ also suggests that 'responsible laboratories [...] should not, as a general rule, undertake the authentication of the undocumented antiquities except possibly to remind the collecting world of the prevalence of fakes and forgeries and thus keep the market depressed. Unfortunately, the likelihood that a piece has been stolen or looted does not seem to deter purchasers; the possibility that it is forged does'.

Fakes intermingle with looted artefacts on the antique market and should therefore be controlled in the same way. Beyond the high financial stakes involved, if fake artefacts are not identified as such, they may help to distort the history of the past, which has been patiently reconstructed by scientists from all kinds of disciplines (archaeology, philology, history, art history and many more). In the scientific world where power and reputation rule just like everywhere else, competition for positions is fierce and the principle of 'publish or perish' prevails, 
making it difficult for some people not to succumb to the temptations of being the first to gain access to a spectacular object. Under these circumstances, it is more important than ever to uphold the highest scientific standards.

\section{Acknowledgements}

Most of the contributions to this volume were presented as preliminary versions at the 2018 conference on Fakes and Written Artefacts (28 February-1 March 2018), which was organised by Sonderforschungsbereich 950 'Manuscript Cultures in Asia, Africa and Europe' and funded by the German Research Foundation (DFG) as part of the work conducted by the Centre for the Study of Manuscript Cultures (CSMC) at Hamburg University. Claudia Colini, Dan Shapira and Jost Gippert's articles have been included because of their direct relevance to the topics discussed here. We wish to thank everyone who participated in the conference, in particular the authors of the different chapters of this book, as well as Caroline Macé, Carl Carter and Laurence Tuerlinckx for their help during the editing process.

\section{References}

Ahituv, Shmuel, Aaron Demsky, Yuval Goren, and André Lemaire (2007), 'The Inscribed Pomegranate from the Israel Museum Examined Again', in Israel Exploration Journal, 57: 87-95.

Barboza, David et al. (2013), 'Forging an Art Market in China', in New York Times, <http://www.nytimes.com/projects/2013/china-art-fraud/index.html > (accessed on 1 April 2020).

Barker, Nicolas (1990), 'Textual Forgery’, in Jones (ed.) 1990, 22-27.

Bloch, Marc (1941), Apologie pour l'histoire ou métier d'historien (Cahier des Annales 3), Paris: Armand Colin.

Bohn, John W. (1999), 'Museums and the Culture of Autography', in The Journal of Aesthetics and Art Criticism, 57/1: 55-65.

Bredekamp, Horst, Irene Brückle, and Paul Needham (eds) (2014), A Galileo Forgery. Unmasking the New York Sidereus Nuncius, Berlin/Boston: De Gruyter.

Casement, William (2015), 'Fakes on Display: Special Exhibitions of Counterfeit Art', in Curator. The Museum Journal, 58/3: 335-350.

Craddock, Paul (2009), Scientific Investigation of Copies, Fakes and Forgeries, London: Routledge.

Drayson, Elizabeth (2013), The Lead Books of Granada (Early Modern History: Society and Culture), Houndmills, New York: Palgrave MacMillan.

Fisher, Jim (2008), Forensics under Fire: Are Bad Science and Dueling Experts Corrupting Criminal Justice?, Piscataway, NJ: Rutgers University Press.

Freeman, Arthur (2014), Bibliotheca Fictiva. A Collection of Books \& Manuscripts Relating to Literary Forgery $400 B C-A D 2000$, London: Bernard Quaritch Ltd. 
Gaber, Hanane, Nicolas Grimal, and Olivier Perdu (eds) (2018), Imitations, copies et faux dans les domaines pharaonique et de l'Orient ancient. Actes du colloque Collège de FranceAcadémie des Inscriptions et Belles-Lettres, Paris, 14-15 janvier 2016, Paris: AIBL-Soleb. Gallop, Annabel Teh (2017), 'Fakes or Fancies? Some "Problematic” Islamic Manuscripts from South East Asia', in Manuscript Cultures, 10: 101-128.

Grafton, Anthony (1990), Forgers Critics. Creativity and Duplicity in Western Scholarship, Princeton: Collins and Brown.

Greenstein, Ed (2016), 'The So-Called Jehoash Inscription: A Post-Mortem', in ASOR Blog, February 2016, IV, No. 2, <http://www.asor.org/anetoday/2016/02/the-so-calledjehoash-inscription-a-post-mortem/> (accessed on 29 March 2020).

Harrist, Robert E. Jr. (2004), 'Replication and Deception in Calligraphy of the Six Dynasties Period', in Zong-qi Cai (ed.), Chinese Aesthetics. The Ordering of Literature, the Arts and the Universe in the Six Dynasties, Honolulu: University of Hawai'i Press.

Havens, Earle (ed.) (2014), Fakes, Lies, and Forgeries. Rare Books and Manuscripts from the Arthur and Janet Freeman Bibliotheca Fictiva Collection, Baltimore: The Sheridan Libraries, Johns Hopkins University Press.

Hiatt, Alfred (2004), The Making of Medieval Forgeries: False Documents in Fifteenth-Century England, London: The British Library.

Higbie, Carolyn (2017), Collectors, Scholars, and Forgers in the Ancient World, Oxford: Oxford University Press.

Jones, Mark (ed.) (1990), Fake? The Art of Deception, Berkeley: University of California Press.

Jones, Mark (ed.) (1992), Why Fakes Matter. Essays on Problems of Authenticity, London: British Museum Press.

Köhler, Peter (2015), Fake. Die kuriosesten Fälschungen aus Kunst, Wissenschaft, Literatur und Geschichte, Munich: C. H. Beck.

Koppenhaver, Katherine M. (2007), Forensic Document Examination: Principles and Practice, Tototwa NJ: Humana Press.

Landon, Richard (2003), Literary Forgeries \& Mystifications. An Exhibition. Thomas Fisher Rare Book Library, University of Toronto, June 18 - August 29, 2003, Toronto: Thomas Fisher Library.

Lehrer-Jacobson, Gusta and Jay C. Jacobson (1989), Fakes and Forgeries: From Collections in Israel. Exhibition and Catalog, Tel Aviv: Eretz Israel Museum.

Lowenthal, David (1990), 'Forging the Past', in Jones (ed.) 1990, 16-22.

Luke, Christina and Morag Kersel (2005), 'The Antiquities Market', in Journal of Field Archaeology, 30: 191-200.

McKusick, Marshall (1991), The Davenport Conspiracy Revisited, Ames: lowa State University Press.

Metzger, Bruce M. (1997), Reminiscences of an Octogenarian, Peabody MA: Hendrickson.

Michel, Cécile (1987), Nouvelles tablettes 'cappadociennes du Louvre' = Revue d'Assyriologie, 81.

Michel, Cécile and Brigitte Lion (2000), 'L'évolution des espèces sur un relief néo-assyrien de Khorsabad', in Akkadica, 118: 1-3.

Michel, Cécile (2019), 'Réflexions éthiques appliquées à l'étude du Proche-Orient antique', in Canadian Journal of Bioethics 2(3), 138-145 (online publication: <https://cjb-rcb.ca/index.php/cjb-rcb/article/view/129> [accessed on 29 March 2020]). 
Müller, Andreas E., Lilia Diamantopoulou, Christian Gastgeber, and Athanasia KatsiakioriRankl (eds) (2017), Die getäuschte Wissenschaft. Ein Genie betrügt Europa - Konstantinos Simonides, Vienna: Vienna University Press.

Museum für Asiatische Kunst (2007): Die Kunst des Fälschens, Berlin: Staatliche Museen zu Berlin - Stiftung Preußischer Kulturbesitz.

Myers, Robin (1996), Fakes and Frauds: Varieties of Deception in Print and Manuscript, New Castle: Oak Knoll Press.

Obi, Lucia and Shing Müller (1997): 'Religiöse Schriften der Yao. Überblick über den Bestand der Yao-Handschriften in der Bayerischen Staatsbibliothek', in Nachrichten der Gesellschaft für Natur- und Völkerkunde Ostasiens, 161-162: 39-83.

Oxford English Dictionary (2020), <https://www.oed.com/> (accessed on 24 May 2020).

Rollston, Christopher A. and Heather Dana Davis Parker (2005), 'Forgeries: A Desideratum for Museums and Collections', in Near Eastern Archaeology, 68: 75.

Rosenblum, Joseph (2000), Practice to Deceive. The Amazing Stories of Literary Forgery's Most Notorious Practitioners, New Castle: Oak Knoll Press.

Schnapp, Alain (1993), La Conquête du passé : aux origines de l'archéologie, Paris: Carré.

Stephens, Walter (2014), 'Discovering the Past: The Renaissance Arch-Forger and His Legacy', in Havens (ed.) 2014, 67-84.

Tait, Hugh (1992), 'Reinhold Vasters: Goldsmith, Restorer and Prolific Faker', in Jones (ed.) 1992, 112-133.

Van Schaik, Sam and Imre Galambos (2012): Manuscripts and Travellers: The Sino-Tibetan Documents of a Tenth-Century Buddhist Pilgrim, Berlin/Boston: De Gruyter.

Vaughn, Andrew G. (1992), 'The Restoration of Classical Sculpture in the Eighteenth Century and the Problem of Authenticity', in Jones (ed.) 1992, 41-50.

Vaughn, Andrew G. and Christopher A. Rollston (2005), 'The Antiquities Market, Sensationalized Textual Data, and Modern Forgeries', in Near Eastern Archaeology, 68: 61-65. 